\title{
Pros

\section{LOS OBJETIVOS DE LAS NOVELAS TESTIMONIALES DE LA GUERRILLA: EL CASO VENEZOLANO}

THE POLITICAL OBJECTIVES OF THE GUERRILLA TESTIMONIAL NOVELS: THE VENEZUELAN CASE

OMAR OSORIO AMORETTI Universidad Simón Bolívar osorioamoretti@usb.ve

RESUMEN: A lo largo del siglo xx, la novela testimonial venezolana se caracterizó por una condena sistemática de las dictaduras militares, haciendo énfasis en las torturas, con lo cual se articuló un imaginario que propiciara la construcción del sistema democrático. Este patrón discursivo se interrumpió con una serie de testimonios que surgieron una vez culminada la lucha armada de los años 60 . ¿Por qué ocurrió ese cambio? ¿Cuáles fueron sus intereses? Proponemos que en estos textos se replantea discursivamente el problema del guerrillero como individuo, pues en tanto perdedor en el conflicto se les impuso una estructura simbólica desde un poder hegemónico que no los representaba y ejercía en ellos una violencia semántica cuyas consecuencias repercutían en el tiempo histórico.

PALABRAS CLAVE: literatura venezolana; testimonio; Aquí no ha pasado nada; Ángela Zago; Los topos; Eduardo Liendo

ABSTRACT: Along the $20^{\text {th }}$ century, the Venezuelan testimonial novel was characterized by a systematic condemn of military dictatorships, making emphasis on the tortures, which allow to articulate an imaginary that could stimulate the democratic system's development. This discursive pattern was interrupted with a couple of testimonies which rise up once the arm conflict was over in the sixties. Why this change happened? Which were its interests? We propose that these texts raise again discursively the problem of the guerrilla as an individual, since as a loser in the conflict it was imposed upon him a symbolic structure from a hegemonic power that did not represented them, exerting a semantic violence on them whose consequences affected them in the historical time.

KEYWords: Venezuelan Literature; Testimonio; Aquí no ha pasado nada; Ángela Zago, Los topos, Eduardo Liendo 


\title{
1. INTRODUCCIÓN
}

Es bien sabido que la aparición de la escritura de corte testimonial en los años 70 en América Latina es el resultado, entre otras razones, de la instalación de dictaduras militares cuyas prácticas opresoras generaron un trauma social. Estas fueron denunciadas reiteradamente una vez que los sistemas que las promovían fueron desplazados del poder político. El estudio del género en sus diferentes formatos por parte de las instituciones académicas privilegió un corpus radicado tanto en el Cono Sur como en Centroamérica, lo que invisibilizó la producción de otras naciones como Venezuela, cuya tradición es incluso anterior a su canonización y ha tenido correspondencia con muchos de los postulados ofrecidos por John Beverley en su célebre "Anatomía del testimonio":

\begin{abstract}
Un testimonio es una narración -usualmente pero no obligatoriamente del tamaño de una novela o una novela corta- contada en primera persona gramatical por un narrador que es a su vez el protagonista (o el testigo) de su propio relato. Su unidad narrativa suele ser una "vida" o una vivencia particularmente significativa (situación laboral, militancia política, encarcelamiento, etc.). La situación del narrador en el testimonio siempre involucra cierta urgencia o necesidad de comunicación que surge de una experiencia vivencial de represión, pobreza, explotación, marginalización, crimen, lucha. En la frase de René Jara, el testimonio es una "narración de urgencia" que nace de esos espacios donde las estructuras de normalidad social comienzan a desmoronarse por una razón u otra. Su punto de vista es desde abajo. A veces su producción obedece a fines políticos muy precisos. Pero aun cuando no tiene intención política explícita, su naturaleza como género siempre implica un reto al statu quo de una sociedad dada. (Beverley 1987a: 9)
\end{abstract}

Sin embargo, durante la lucha guerrillera de la década de los 60 hay un parteaguas importante en el proyecto creador de sus autores que muestra nuevas formas de proferir un discurso. Este, desde los márgenes de enunciación propios del sujeto históricamente dado, desautoriza al lenguaje emanado desde las instancias de poder más relevantes en el plano político.

Ante esto, nos preguntamos cuál ha sido el devenir histórico de la literatura testimonial venezolana hasta ese momento, cuáles han sido las causas históricas impulsoras de esta diferencia de perspectiva a mediados de la centuria pasada, así como de qué manera se articulan las narraciones de Ángela Zago (Aquí no ha pasado nada, 1972) y Eduardo Liendo (Los topos, 1975) para cuestionar tanto la exégesis promovida por el aparato comunicacional detentado por los sectores democráticos del país como el lenguaje empleado por estos para habilitar la exclusión de aquellos hombres que, en tanto perdedores en el conflicto armado, cargaron a cuestas una representación imprecisa e insuficiente de su identidad. Esperamos con esto no solo iluminar el espectro mediante el estudio de nuevos exponentes hasta entonces desconocidos sino también argumentar que la diferencia básica de estos testimonios radica en que, a diferencia de la clásica formulación de denuncias de la violencia emanada de gobiernos tiránicos, el discurso se centra en la construcción indentitaria del sujeto guerrillero, en 
vista de que sus protagonistas han perdido la posibilidad de acceder al poder y ahora sufren una violencia simbólica por parte de las instituciones estatales que deforma su imagen ante la historia. Apelar a una retórica testimonial que construya su intimidad será para estos escritores la única manera de desmantelar la ideología hegemónica que los envuelve.

2. La narRativa testimonial de la tiranía CAStrense (1908-1958). El testigo, COMBATIENTE Y JUEZ

En la historia venezolana del siglo pasado hay tres grandes periodos importantes que incentivaron la gestación de novelas testimoniales. El primero de estos ocurre a principios de la década de los veinte, durante la dictadura del general Juan Vicente Gómez (1908-1935), última cabeza de la tiranía andina; el segundo surge a principios de los 60, una vez derrocada la dictadura de las Fuerzas Armadas, de la cual el doctor Germán Suárez Flamerich y los militares Carlos Delgado Chalbaud y Marcos Pérez Jiménez eran sus servidores y representantes temporales respectivamente (1948-1958). Por último, la etapa final la encontramos a mediados de los años 70, una vez culminado el conflicto armado entre los miembros del Partido Comunista de Venezuela y el gobierno liberal democrático representado por Acción Democrática (1959-1969). La mayoría de sus autores se opusieron a los regímenes de turno por la vía armada, lo que les llevó a padecer la violencia de su aparato represivo. Sus publicaciones vieron la luz durante la vigencia de los regímenes que combatían o poco tiempo después de que estos fueron sustituidos. Fue el caso de textos como La vergüenza de América (1921) de José Rafael Pocaterra, En las huellas de la pezuña (1929) de Rómulo Betancourt y Miguel Otero Silva, Puros hombres (1938) de Antonio Arráiz durante la tiranía gomecista; de Se llamaba SN (1964) o Guasina. Donde el río perdió las 7 estrellas (1969) de José Vicente Abreu durante el autoritarismo castrense. A pesar de las distancias cronológicas existentes entre los gobiernos que representan estos autores en sus páginas, todos mantienen una afinidad en sus objetivos que les permite ser leídas como un bloque compacto: tienen el insistente interés en delatar una realidad dantesca y agresiva, incompatible con la imagen pública que los gobernantes promovieron a través de la propaganda y las relaciones internacionales. En muchos de ellos la representación de los protagonistas de los eventos suelen ser maniqueas, no pocas veces en su afán de conmover la opinión pública e inducirla a condenar lo ocurrido.

Pues bien, ¿por qué existe una continuidad programática en estos textos tan lejanos entre sí? Muchas son las causas, pero nos interesa en especial destacar la siguiente: porque se trata del testimonio de figuras que salieron triunfantes en la contienda política librada. Al hecho de que el desplazamiento de las dictaduras tanto andina como pretoriana les permitió a los sobrevivientes de la tortura enarbolar sin ningún tipo de restricción una narrativa privada de proyección pública destinada, por una parte, a deslegitimar simbólicamente la actuación histórica de una élite y, por otra, arroparla bajo una nueva simbología (la suya) debe sumársele que la llegada de una nueva dirigencia a cargo de los 
destinos de la nación contribuyó, ya por inacción, ya por difusión, a mantener ese mensaje que, de tanto leerse a través de las generaciones, de tanto estudiarse en las universidades, de tanto recordarse en los periódicos, terminó por adquirir estatus oficial para la ciudadanía.

Esto resulta capital para entender el fenómeno. Si, como sabemos, no suele haber medias tintas para definir a nuestros rivales, las posibilidades de resaltar sus cualidades negativas siempre serán altas cuando se nos pregunte sobre él con total libertad. La narrativa testimonial venezolana desde Gómez hasta las Fuerzas Armadas, al provenir de hombres protegidos por las alas de la victoria, fue escrita sobre una tabula rasa donde los escritores, hasta ayer marginados y ahora detentadores de un poder simbólico insospechado, hacían borrón y cuenta nueva con el pasado reciente para legarlo al futuro. Por ello la denuncia del crimen y el castigo corporal recibidos es tan necesaria y reiterativa en su discurso: en la medida que se delatan las taras del sistema anterior, se condenaba su potencial regreso y sobre todo se reafirmaba el nuevo proyecto que aspiraba sustituirlo: el régimen democrático liberal.

\section{NueVAS CONDICIONES POLÍtico-SOCIALES EN EL VIRAJE DE LOS INTERESES DE LA NOVELA TESTIMONIAL DURANTE EL PERIODO DEMOCRÁTICO (1959-1969)}

Este no fue el caso de la novelística testimonial guerrillera. Ciertamente, algunos de estos rasgos perviven en uno que otro exponente, pero lo destacable aquí es que, mientras en las décadas anteriores predominaba en sus textos un carácter acusatorio y de denostación, el nuevo contexto donde se producen estas narraciones impulsa a sus creadores no tanto a expresar la condena de un régimen violento sino a derrumbar lo que para ellos es un mito erigido por este para la posteridad: la imagen del sujeto guerrillero como estereotipo de la delincuencia organizada, de carácter sanguinario, violento, servil a potencias extranjeras y no exento de cierta fatuidad propia. Este será el proyecto más destacado y novedoso que ostenten en su construcción. Su ruptura cobra mayor importancia cuando se coteja con casos muy cercanos cronológicamente como Nicaragua, donde, a raíz del triunfo de la Revolución Sandinista, "el testimonio se convirtió en una forma de lucha ideológica, de abierta resistencia ante las barbaries de las autoridades y en busca de solidaridad internacional" (Rueda Estrada y Vázquez Medeles 2015: 483).

Producto de una tensión político-social en la cual el Gobierno de Rómulo Betancourt no vaciló en tomar medidas violentas para mitigarla, ${ }_{1}^{1}$ la crítica de

\footnotetext{
1 Esto ocurre cuando las protestas, muchas de ellas lideradas por dirigentes del Partido Comunista de Venezuela, devinieron en acciones terroristas, tal y como lo señala el presidente el 21 de enero de 1960: "De los panfletos explosivos se pasó a las bombas explosivas por los irreductibles enemigos de la paz y de la felicidad de los venezolanos [...]. Contra el bandidaje armado ya no cabían fórmulas civilizadas. Y por eso se impartieron instrucciones a las Fuerzas Policiales y a las Fuerzas Armadas de Cooperación para que disparara, y no al aire, contra cualquier persona o grupo de personas que se localizase in fraganti en el momento de lanzar o depositar cargas de dinamita en algún sitio de la ciudad. No fue encontrado ningún protagonista de actos terroristas con las manos en la masa, pero para hoy y para siempre debe quedar claro ante el país que la
} 
la izquierda al sistema democrático reinstaurado encontró en el ejemplo de la Revolución cubana una aparente panacea al problema: la acción guerrillera. Las razones, repetidas durante todo el periodo bélico, tienen en la intervención de Fabricio Ojeda en el Congreso Nacional el 30 de junio de 1962 una de las mejores síntesis. Más aún: en tanto intelectual que interviene en el corazón de la república, su discurso irrumpe de manera directa en la esfera pública y trama desde el centro de poder una exégesis en el plano doctrinario cuyo impacto insta a la deslegitimación de los representantes del sistema democrático y autoriza simbólicamente la ejecución de una empresa vetada por la ley. Es por ello que Ojeda, presidente de la Junta Patriótica en el año de 1958 y posteriormente diputado de Unión Republicana Democrática, toma la decisión de renunciar a su curul y asumir la causa de la vía armada bajo el argumento de que se necesita un cambio verdadero que solucione los problemas de la nación. Estos problemas, heredados de la dictadura militar, se han acentuado en el sistema democrático, pues desde el 23 de enero hasta la fecha quienes gobernaban "sirvieron como instrumento a aquellos intereses que gravitan en forma negativa sobre el cuerpo desfalleciente de la Patria" (2009: 14), con lo cual terminaba por realizar un juicio autocrítico sobre el proceso histórico vivido luego de la caída del general Pérez Jiménez:

El 23 de enero hubo solo esto: un cambio de nombres. La oligarquía explotadora, los servidores del imperialismo buscaron acomodo inmediato en el nuevo gobierno. El poder político había quedado en manos de los mismos intereses y los instrumentos de ese poder seguían bajo la responsabilidad de las mismas clases. (Ojeda 2009: 15)

Esta exposición de los problemas nacionales delata de forma clara y precisa la intención subyacente: ante un período de la historia que se consideró como transformador y que en realidad no fue sino "un cambio de nombres"; ante un gobierno que continúa los vicios del pasado y cierra de esa manera su posibilidad de cambio; ante una estructura política que se interesa únicamente en mantener sus privilegios en detrimento de una población mayoritariamente pobre y de la soberanía nacional solo es posible el cambio a través de la fuerza. La lucha armada, por tanto, no es una opción: es una necesidad.

Siguiendo con la exhibición de razones para combatir al sistema, Ojeda acusa al gobierno de Betancourt de continuar "allanando hogares, apresando ciudadanos sin delitos" (2009:17) a pesar de que el Congreso Nacional había restablecido las garantías constitucionales. Líneas después denuncia que:

... al amparo de un decreto pérezjimenista que el pueblo derogó el 23 de Enero [sic], se prohíbe a la Unión Nacional de Mujeres un acto en el Palacio de los Deportes de Caracas para hablar sobre la devaluación del bolívar y su incidencia en el ya alto costo de la vida; al amparo de ese mismo decreto, el gobierno de

orden impartida a los organismos armados encargados de la custodia de la tranquilidad pública [...] es esta: sobre quien sea ubicado por un cuerpo armado colocando una bomba o lanzándola, se aplicará la última ratio de una descarga" (Betancourt 1968a: 203). 
Betancourt prohíbe a los trabajadores, a la clase obrera revolucionaria celebrar el $1^{\circ}$ de Mayo, Día Internacional del Trabajo. Y por si ello fuera poco, los agentes de la represión policial, sus bandas armadas, arremetieron contra obreros indefensos, que desafiando el terror salieron a la calle para conmemorar su día con dignidad. (Ojeda 2009: 17)

Esto sucesos, continúa el diputado, "no son hechos aislados de la arbitrariedad transitoria, sino norma y razón de ser de un gobierno al margen de la ley, que no respeta la Constitución, ni respeta el Congreso, ni respeta nada" (2009: 18). Dicha situación, se presume, seguirá igual de no llevarse a cabo el cambio profundo que se aspira desde la caída dictatorial. Por ello "obligados por la brutal represión del gobierno que amenaza con la muerte, la tortura y la cárcel a quienes se oponen a sus designios" (2009: 23), y en vista de que "el grupo que gobierna ha demostrado hasta la saciedad que solo conoce el método de la violencia, el camino de la ilegalidad" (2009: 24), se concluye que:

... no cabe otra actitud [sino] [...] disponerse a combatirlo con sus mismos métodos, para que los venezolanos puedan, libres del Gobierno de Betancourt, libres de sus odios e intrigas, de su corrupción e incapacidad, de su politiquería y pequeñez moral, de su sectarismo y maldad, darnos un gobierno verdaderamente nacional, respetuoso de la ley democrática, fiel servidor del pueblo y leal a la independencia y soberanía nacionales. (Ojeda 2009: 24)

Pero este combate, a diferencia de lo que podría pensarse, está lejos de ser una lucha en contra de las instituciones democráticas. En esto el orador resulta categórico:

No hacemos las armas contra el Ejército, la hacemos contra quienes sirven a los monopolios extranjeros causantes de nuestra pobreza; hacemos la guerra, contra los asesinos de estudiantes, de obreros, de campesinos; hacemos la guerra contra los que roban y comercian a nombre de una democracia falsa; hacemos la guerra contra los que siembran el hambre, la angustia y el dolor en la familia venezolana; hacemos la guerra contra una vida de corrupción, de odios e intrigas; en fin, hacemos la guerra para que la aurora de la libertad y la justicia resplandezca en el horizonte de la Patria. (Ojeda 2009: 26)

Al definir al gobierno democrático como negador de todo lo que significaba progreso en materia política (libertades civiles, garantías constitucionales, actitud patriótica y soberana, etc.) y mantener los mismos aspectos de la dictadura (entrega del capital nacional a las compañías extranjeras, empobrecimiento de la población, empleo abusivo de las fuerzas represivas, violación constante a la constitución), este deviene en descrédito y se transfigura ante los ojos de los espectadores en un sistema tiránico cuya única forma de hacerle frente es a través del ejercicio de la violencia.

Esta visión expuesta por Ojeda constituyó durante años el punto de vista de un sector intelectual de la población, así como el motivo para iniciar la lucha 
guerrillera tanto rural como urbana. ${ }^{2}$ La elaboración racional y orgánica de este grupo de ideas que justificaran su actuación posterior contribuyó a la edificación de una imagen idealizada de aquellos seres que alguna vez estuvieron dentro del marco de la legalidad y pronto armaron sus mochilas para emprender la labor subversiva. Porque no hay guerra en el nombre del mal. Así, valores como la abnegación, el heroísmo, el coraje y la justicia se convirtieron en pilares constituyentes del imaginario del sujeto guerrillero para quienes favorecen su cometido. El primer polo de interpretación simbólica sobre los protagonistas de ese momento se había enarbolado.

No obstante, en el decurso de esa guerra irregular de baja intensidad que se vivió durante casi diez años en ese espacio que Orlando Araujo llamó alguna vez la "Venezuela violenta", a diferencia de Abreu o Pocaterra, quienes resultaron vencedores no fueron los atacantes, sino los defensores del sistema presidido. Aquellos no asumieron al final de la contienda posiciones de poder. Al final de la jornada son los grandes perdedores en tres grandes ámbitos de acción muy sensibles.

La primera derrota es de carácter militar y ocurre cuando en 1967 el VII Pleno del Partido Comunista, después de haber asumido la "guerra prolongada de guerrillas" en 1964 (aunque ya la practicaban como mínimo desde el 63), asume su capitulación y estimula el "repliegue" bélico para sumarse a la vida democrática nacional. La segunda es de índole ideológica y es perceptible en las elecciones de diciembre de 1968, cuando, articulados políticamente sus miembros bajo una organización temporal llamada Unión Para Avanzar, pierden ante la figura de Rafael Caldera, con lo cual el pueblo no solo les daba la espalda en aquella fase de guerra anterior sino también en los proyectos ideados durante la paz. El último espacio perdido es el simbólico y tiene que ver con la proyección histórica negativa que pesó sobre ellos una vez mitigado el conflicto.

Uno de los responsables de esta imagen fue el mismo Rómulo Betancourt, quien en tanto líder del proceso de instalación del sistema democrático en el país se valió de las instituciones oficiales para dirigir una serie de discursos con los cuales producir un sentido específico acerca de la imagen del guerrillero, ligado ahora a nociones cónsonas con la criminalidad tales como la ilegalidad de sus acciones, la peligrosidad inherente a estas y el antipatriotismo de su carácter. Pero en el fondo hay más que una apropiación del sentido: existe además un monopolio del lenguaje, pues al decir de Michel Foucault "el discurso no es simplemente aquello que traduce las luchas o los sistemas de dominación, sino aquello por lo que, y por medio de lo cual se lucha, aquel poder del que quiere uno adueñarse" (1992: 12). En la medida en que los significados construidos

\footnotetext{
2 Elena Plaza analiza los documentos emitidos por el Comité Central del PCV en los cuales expone, a través de un análisis marxista, otros argumentos para ejercer la violencia como forma de cambiar el sistema político. Véase al respecto El 23 de enero de 1958, Caracas, Universidad Central de Venezuela, pp. 170-177. Por otro lado, cabe destacar que, al final de su mandato, Betancourt deja una fuerte actividad guerrillera en el país, no así las asonadas militares, las cuales desaparecen en la década de los sesenta. Quedarán en las manos del gobierno de Raúl Leoni (1964-1969) la derrota definitiva de esto grupos armados y su pacificación, hecho que se materializa definitivamente en el primer gobierno de Rafael Caldera (1969-1973).
} 
acerca de la naturaleza de los revolucionarios alzados en armas transitan en la sociedad según las reglas establecidas desde los mecanismos de control discursivos avalados por el Gobierno democrático, los significantes que permiten ponerlos en escenas con una sintaxis específica permanecen como posesión de un sector que tuvo la voluntad de acuñarlos y ponerlos en circulación. Su caracterización, en consecuencia, le confirió un estatus que les permitió a quienes detentaban el mando excluirlos e inhabilitarlos físicamente, políticamente, socialmente y simbólicamente en aras de homogeneizar y armonizar la convivencia dentro de su entorno.

Así, el lenguaje oficial hace de la presencia guerrillera un riesgo para las instituciones democráticas y la vida en sociedad:

... los agentes en Venezuela del señor Kruschev y del señor Fidel Castro son responsables del asesinato por la espalda de policías uniformados y de miembros de las fuerzas armadas, de atracos a bancos y a empresas comerciales e industriales; del fomento y estímulo de las guerrillas nonatas; de cooperación inductora y activa de rebelión armada en las bases navales de Carúpano y Puerto Cabello; en fin, de atentados contra las personas y las propiedades con el confeso y definido propósito de crear un caos en el país y de conducirlo a la guerra civil. (Betancourt 1968b: 248)

El uso del terrorismo mediante el sabotaje forma parte de sus operaciones, todas de corte delictivo. La exposición pública de las infracciones contra el orden público convierte a sus ejecutores en seres antisociales. De esta forma se evitaba un posible vínculo entre estos grupos y los sectores populares del país:

Asesinaron [se refiere a los grupos terroristas de izquierda] a un profesor en su propia aula, en la que dictaba lecciones de cultura y de civismo. Han asaltado establecimientos comerciales, especialmente de firmas inversionistas de Estados Unidos en Venezuela. Han asesinado a funcionarios del orden público; han dinamitado puentes. (Betancourt 1968c: 302).

Este mismo proceso de deslegitimación ocurre con el Partido Comunista de Venezuela y el Movimiento de Izquierda Revolucionaria, sobre los cuales explica Betancourt que:

... ya han perdido su contextura de organizaciones políticas y se han transformado en sectas paramilitares, sometidas a órdenes que se imparten verticalmente de asesinar, robar, incendiar, dinamitar, para adquirir méritos, como ejecutores dóciles de órdenes emanadas del extranjero, ante los sínodos de Moscú y de La Habana. (Betancourt 1968b: 249).

Pero no solo en sus numerosas alocuciones a la colectividad se encargó de señalar que la lucha que se gestaba no era contra las ideas de ciudadanos comunes, pues una vez sucedido en el cargo por Raúl Leoni publicó libros donde los analizó de manera retrospectiva, con lo cual ejerció una influencia notable en 
la interpretación de ese pasado inmediato tan convulso y a su vez tan atrayente para los estudiosos del momento:

\begin{abstract}
Más que revolucionarios, según la clásica interpretación de la palabra, son rebeldes, "rebeldes sin causa", que en el epiléptico comunismo habanero ha encontrado un patrón al cual ajustar su rechazo del mundo dentro del cual viven. Asesinan por la espalda a policías con la misma irracional adhesión a la violencia de los blousons noirs franceses cuando golpean con las cadenas de sus bicicletas al primer transeúnte que pase al lado suyo. Se dejan crecer las barbas con similar alarde de individualización capilar con que los innumerables fanáticos de los Beatles ingleses exhíben [sic] sus largas melenas en las calles de Londres. Son la versión política del pavito caraqueño, primos-hermanos del teddy boy inglés y del angry young man norteamericano. (Betancourt 1969d: 127-128)
\end{abstract}

Esto lo escribe cinco años después de haber dejado el poder. Su interpretación se mantiene sobre los mismos argumentos que expuso durante su gobierno, aunque ahora bajo un discurso mucho más analítico y menos virulento que en los años anteriores, sin por ello adoptar posiciones complacientes con quienes para él fueron los representantes de un movimiento antinacional que "[a]doptando la variante habanera" abandonó la forma tradicional y civilizada de pugna política y se transformó en una organización terrorista que usó como argumentos dialécticos "la bomba de dinamita; el asesinato por la espalda de policías; los asaltos a institutos bancarios, atracos a mano armada rotulados ahora como 'expropiaciones revolucionarias'" (Betancourt 1969d: 124).

La reiteración de este discurso durante la lucha armada y después de obtenida la victoria termina por configurar una visión de los vencidos en términos absolutos. A la fotografía otrora levantada por sus líderes le había surgido un nuevo negativo, mayoritariamente aceptado por los ciudadanos, como puede desprenderse del apoyo que le brindó en plena contienda. ${ }^{3}$ El guerrillero ahora es el equivalente a un delincuente altamente preparado, un asesino sin piedad, un bandolero sin gloria, un disidente del progreso y la modernidad políticos, un partidario de antiguos sistemas dictatoriales, un ser arrodillado ante los intereses de la Unión Soviética y Cuba, un traidor a la patria y sus valores constitutivos, un falso revolucionario que desea instalar un calco del modelo de gobierno fidelista y un rebelde sin causa que hace del terror una doctrina. El segundo polo

\footnotetext{
${ }^{3}$ Esto fue posible gracias a una estrategia basada en "apelar directamente al pueblo, convocándolo a la edificación de un régimen cuyos rasgos y signos eran básicamente comprensibles, por ser en buena parte conocidos [...]. En las plazas públicas, mediante la radio y luego en la televisión, la figura conocida de un hombre que no se daba ínfulas de grandeza, que empleaba conceptos inteligibles incluso para los analfabetos, cuya incorporación a la ciudadanía había promovido [...] contrastaba con las abstracciones y los enrevesados argumentos de figuras públicas poco o nada conocidas, que se presentaban como profetas de un porvenir tan luminoso como ininteligible, para la casi totalidad de la sociedad, dada la brutalidad del mensaje esencial, que consistía en la afirmación de que el régimen sociopolítico liberal democrático, producto del ejercicio pleno de la soberanía popular, y avalado por todos los partidos democráticos, no era bueno para el mismo pueblo que lo eligió" (Carrera Damas 2013: 327-328).
} 
de interpretación había llegado para quedarse, luego de desplazar la legitimidad de la argumentación proferida por Ojeda en 1962.

A partir de este momento se ha producido ya no una violencia física (la cual padecieron los cuerpos de los combatientes durante la guerra) sino aquello que Slavoj Zizek entiende como "violencia simbólica" en su manera más primaria, a saber, aquella "que está relacionada con el lenguaje como tal, con su imposición de cierto universo de sentido" (2009: 10). El cúmulo de valores que cursaron libremente y de forma discursiva sobre el talante del sujeto guerrillero a través de estudios históricos, escritos periodísticos, reportajes televisivos y el habla común de los ciudadanos no solo terminó por establecer condiciones mentales que permitieron reproducir ciertos valores con los cuales sostener la estructura de control político del sector democrático: también impuso desde el mismo momento en que ese lenguaje se moduló una semántica que penetró las identidades de los combatientes en el mismo acto de nombrarlos y los transformó contra su voluntad. Estas novelas testimonios que estudiaremos a continuación se dirigieron a la demolición de este fenómeno.

4. Revelar al individuo, desmantelar la ideología. El deSMONTAJe del imagiNARIO GUERRILLERO A TRAVÉS DEL DISCURSO TESTIMONIAL

Una vez concluido el periodo de lucha a raíz de la política de pacificación iniciada en los últimos años del gobierno de Raúl Leoni, la cual habrá de heredar la primera presidencia de Rafael Caldera, proliferó la producción tanto de materiales ficcionales inspirados en los eventos pasados como de narrativas testimoniales. En el caso que nos corresponde, Aquí no ha pasado nada (1972), de Ángela Zago, y Los topos (1975), de Eduardo Liendo, conforman la lista de testimonios que se alejan de la tradición oral que sirvió para canonizar el término y toman la experiencia vivida en la guerrilla y en la prisión respectivamente como material fidedigno con el cual contrarrestar esa interpretación oficial que había calado hondo en la población. ${ }^{4} Y$ es que en el fondo la pérdida de la guerra los había relegado a un estatus periférico dentro de las esferas sociopolíticas del país que les hacía imposible tomar otra, digámosla así, "estrategia escrituraria" sin estar condenada a perder su efectividad. En consecuencia, quienes deseaban escribir en este momento histórico se hallaban en una posición subalterna, esa que designa, al decir de Ranajit Guha, "un atributo general de subordinación [...] ya sea que este sea expresado en términos de clase, casta, edad, identidad sexual, profesión o de cualquier otra manera" (Beverley 2011b: 33). Dicha condición saltaba a la vista:

\footnotetext{
4 Ángela Zago llegó a manifestar este fenómeno como impulsor de la escritura de Aquí no ha pasado nada: "[P]ara el momento existía en mi país abundante y confusa información acerca de estos sucesos. Esta información se podía resumir en pocas palabras: quienes defendían a los guerrilleros afirmaban que éramos héroes extraordinarios, superhombres o supermujeres en estado de perfección: sin dudas, ni errores, ni miserias, amores, odios... irreales. Quienes nos adversaban sostenían ciertos criterios opuestos: prostitutas, asesinos, bandoleros, terroristas, inadaptados. Ambos mentían y los verdaderos protagonistas de estos acontecimientos ya para ese entonces, estábamos dentro de una realidad dolorosa, frustrante e insegura. Los cimientos filosóficos y humanos que nos habían sostenido parecían asentarse en un pantano profundo" (Zago 1993b: 27).
} 
eran comunistas en un espacio democrático, no tenían voz autorizada dentro de las instituciones del sistema, carecían de prestigio social con el cual hacer valer sus ideas e incluso muchos de ellos apenas tenían una formación intelectual incipiente (Zago era una estudiante de Comunicación Social y Liendo adquirió sus primeras lecturas intensivas estando en prisión), por lo que acá la escritura responde a una perentoriedad ajena a los intereses comunes del hombre de letras tan conocidos durante todo el siglo xIX y principios del xx en el país.

Se trata entonces de la producción de textos con ese "carácter de urgencia" que hemos visto con la definición del término hecha por Beverley, pero una urgencia que en estos momentos es ante todo de carácter simbólico, pues materialmente (valga decir doctrinariamente, militarmente) todo estaba perdido. Sin embargo, existía la posibilidad de brindar una visión personal de los hechos que contrastara con el estereotipo que se había establecido desde el poder que, como se vio, básicamente constituía, junto con el discurso de las figuras públicas comunistas, una de las visiones en contraste: héroes ilustres (Fabricio Ojeda) o asesinos serviles de potencias extranjeras (Rómulo Betancourt). En el caso de Zago, esto le impulsa a escribir en 1972 Aquí no ha pasado nada desde una intencionalidad histórica en detrimento de una función poética de lo narrativo, la cual es pensada y utilizada con una finalidad auxiliar. ${ }^{5}$ Lo de histórica no lo mencionamos en el sentido de colindar con la historiografía, sino de elaborar una experiencia que pueda contribuir a un conocimiento más complejo de la conmoción social vivida. ${ }^{6}$

Es el mismo caso de Los topos de Liendo, si bien el narrador llega a expresar que escribe esa historia "para que la lean los nietos: para nada más. No hay en ella ninguna lección" (1975: 95). Pero el hecho de tener, como llegara a confesar recientemente, que contarla para evitar que el olvido fagocite su existencia ${ }^{7}$ implica transmitir, aunque sea de manera indirecta, imágenes de un pasado a las cuales resulta imposible privarlas de valor y sentido.

De esta manera, la focalización interna de una voz autodiegética tanto en la narración de Aquí no ha pasado nada como en la de Los topos es percibida por el lector como la representación de los mismos autores que en calidad de testigos construyen aquel mundo imposible de conocer desde la cumbre del poder político gracias a los elementos tanto paratextuales como históricos que

\footnotetext{
${ }^{5}$ Este elemento será una constante en el resto de su producción textual: "Preciso que la idea es más de comunicación que de proposición literaria. No tengo proposiciones literarias. [...] Nunca me he sentado ante la máquina de escribir con un esquema pre-hecho. Pienso muy a lo periodista: debo atrapar al lector" (Zago 1993b: 31).

6 Es lo que ha manifestado cuando se le ha preguntado si el testimonio puede dar la verdadera perspectiva de lo que fue la guerrilla venezolana: "Yo creo que lo que falta es otro tipo de trabajo. Creo que el trabajo testimonial es muy localizado y muy de lo que es uno. Supóngase, si yo escribo mi testimonio, es mi posición ante la vida en general y ante el movimiento. Y ahí, por supuesto, como todo ser normal y corriente está mi subjetividad, mi pedacito de esa situación. Pero yo creo que hace falta trabajos de investigación en profundidad" (Freilich de Segal s.a.: 297).

7 "Yo la condición de militante me la tomé enserio [sic], y poco tiempo después ya estoy en la montaña a los 20 años con Argimiro Gabaldón y el primer comandante Gregorio Lunar Marquez [sic]. Toda esa historia la escribí en Los Topos para no tener que contarla más y que no se perdiera en la memoria" (Cubas 2016: en línea. Subrayado nuestro).
} 
gravitan sobre el receptor al momento de establecer su decodificación (sobre esto hablaremos líneas abajo). Es algo muy similar a lo que ocurre con el género de la autobiografía y que Philippe Lejeune cataloga como "pacto autobiográfico" al señalar que este "es la afirmación en el texto de esta identidad [se refiere al nombre en el relato], y nos envía en última instancia al nombre del autor sobre la portada" (1994: 64), con lo cual se establece una correlación indisoluble entre las figuras de "autor", "narrador" y "personaje", las cuales coinciden aunque desde distintos niveles.

Si asumimos que toda elaboración lingüística posee dentro de sí una serie de reglas internas capaces de validar la información al remitente, entonces debemos hacer nuestras las palabras de Beatriz Sarlo cuando señala la existencia dentro del testimonio, sin importar cuál sea el formato empleado para materializarse, de una retórica que en el plano narrativo cataloga de "realista-romántico". Romántico en tanto predomina una primera persona del singular o en su defecto una tercera elaborada bajo la táctica del discurso indirecto libre donde el narrador "confía en la representación de una subjetividad y, con frecuencia, en su expresión efusiva y sentimental" (2007: 75). La cualidad realista, en cambio, asume que "la acumulación de peripecias produce el saber buscado y que ese saber podría tener una significación general" (2007: 76). Este modelo les permitirá a las narraciones de Zago y Liendo generar una serie de estrategias frente al lector con las cuales incentivar el carácter de verosimilitud de sus enunciados. El intimismo de los protagonistas, elaborado sobre la base de un yo, expresa la condición interna del sujeto guerrillero no en tanto víctima de un sistema injusto (como en su momento fue construido el testimonio de las dictaduras en Venezuela), sino en tanto ser humano de carne y hueso, lo que permite bordear el maniqueísmo típico prevaleciente en una sociedad polarizada por la conflagración anterior. "Quisiera leer un libro -escribe Morela, pseudónimo de Zago durante la guerrilla- donde la gente sea gente. Pero en estos libros, los contrarrevolucionarios son todos unos coños de madre y los camaradas puros héroes" (1975a: 152). Es por ello que la exposición de las vivencias ocurridas en el Frente Simón Bolívar ${ }^{8}$ durante los años 1964 y 1965 es vista desde el prisma ideológico y termina por contrarrestar la visión de la izquierda sobre la lucha armada.

Veamos cómo ambos textos se arman con el objetivo de desarticular el discurso oficial sobre el tema. Desde el punto de vista de la escritura, un aspecto clave se encuentra en el problema de la representación. ¿Cómo hacer creíble lo escrito? Afianzados en el modelo realista para construir narrativamente su experiencia, los dos escritores retratan una realidad que se asume fija y constatable para los lectores cuando, amparados en los paratextos que funcionan como marcos garantes de la verdad, se construyen espacios y sujetos públicamente conocidos como la isla de Tacarigua o el dirigente político Teodoro Petkoff en el caso de Liendo y las montañas de Lara o el líder guerrillero Argimiro Gabaldón en el de Zago, quien además recurre en sus ediciones a imágenes de los perso-

${ }^{8}$ Este frente abarcaba los estados Lara y Portuguesa. En el primero prestó servicios en la brigada 21. 
najes mencionados en la trama en calidad de anexos, como si con ello tratara de corroborar la veracidad de sus palabras y darles una dimensión más palpable. Esto le otorga solidez a la idea del referente, vale decir, a la concepción de un mundo exterior reflejado, aunque con ciertas limitaciones, en el lenguaje, tal y como señala Elzbieta Sklodowska cuando dice que el testimonio "takes place only if the reality of a referent is established and in order for this to happen all silent negations must be withdrawn and the authority of the witness, addressee's competence, and languaje's ability to signify must be assured" (1996: 87). ${ }^{9}$

Esto se percibe incluso antes de abrir los libros. La primera edición de Los topos señala en su contraportada que Liendo narra "su propia experiencia de hombre que fue a las montañas, su implicación en una lucha armada que al final se revela absurda, su captura y los continuos y frustrados intentos para escapar" (1975: contratapa), mientras que en la de Aquí no ha pasado nada se asegura que el título "es la frase final de este libro y la primera amarga reflexión de Angela [sic] Zago, al regresar a Caracas, su ciudad natal, después de haber transcurrido un año y medio organizando la guerrilla en las montañas" (1975a. contratapa). Estas señalizaciones sin duda conforman uno de los pilares para generar un efecto de verdad en la construcción de la historia (los otros son la elaboración del detalle minucioso de las historias y el uso de recursos intertextuales), de manera que cuando los protagonistas de ambos libros narran el lector termina asumiendo que ese "yo" no es una entidad ficticia, sino un trazo discursivo de algo real que demanda de él una actitud ética marcada por la solidaridad.

Es así como la escritura es reconocida en su decodificación como un puente a través del cual las cosas pueden ser aprehendidas, como si esta fuera un vehículo que, insistimos, a pesar de sus fallas, permite acercarse a lo ocurrido porque los dispositivos que lo acompañan (artificios que, desde luego, son normas culturalmente instauradas) garantizarían su autenticidad. Con todo, el hecho de usar una modalidad realista no hace de estos escritos adalides de una estética burguesa. La inclusión de la realidad política de su momento con el fin de moldear la conciencia del receptor tiene como consecuencia la erección de una práctica antiliteraria que inhabilita los modos tradicionales de lectura a favor de unos más ligados a una comunión entre escritor y lector. Ya lo decía Santiago Colás:

\begin{abstract}
Whereas literature betrayed the alienating and oppressive differences of class, race and imperialism, the testimonio seeks to establish identities: between protagonist and collective, between researcher and protagonist -and, consequently, between reader, researcher, protagonist, and collective, between present subject and objective history, and between the written and the living, spoken language". (Colás 1996: 161) ${ }^{10}$
\end{abstract}

\footnotetext{
9 "[T]oma lugar solo si la realidad de un referente está establecida y, para que esto ocurra, todas las negaciones silenciosas deben ser retiradas y la autoridad del testigo, las competencias del destinatario y la habilidad del lenguaje para significar deben estar aseguradas". Todas las traducciones son nuestras.

10 "Mientras la literatura traicionaba las alienantes y opresivas diferencias de clase, raza e impe-
} 
Los valores heredados como la "belleza", la "ficción" o el "juego" son suspendidos durante este tipo de enunciación debido a la elaboración de una lengua estándar carente en muchos casos de una voluntad de estilo (más notorio en Zago que en Liendo) y la construcción de un tema apremiante y sensible que ha marcado al colectivo socialmente. Todo eso da paso a la manifestación de componentes atípicos dentro de una tradición literaria como los de "verdad", "denuncia" y "univocidad del sentido". Esto será clave cuando el contenido sea asimilado por el lector: este perderá cualquier riesgo de caer en ambigüedades y su exégesis tendrá coordenadas fijas en todo momento, lo que les permitirá a los autores construir ciertas identidades de sujetos marginados que, de ser aceptadas, modificarán la opinión pública de su sociedad, en vista de que se trata de mecanismos internos y externos que logran darle un orden sólido al texto y con ello un significado con mayores probabilidades de ser comprendido.

Gracias a esto, en Aquí no ha pasado nada, percibimos que el desarrollo de la interioridad femenina de Morela se construye a través de la exposición pública (no se olvide que el texto es publicado) de todo lo relacionado con su cuerpo que, a diferencia de los estereotipos, es débil y vulnerable a la enfermedad, al hambre, a la sangre:
Ha llegado mi primera menstruación en las montañas. Vino con una diarrea ho- rrible y fiebre. No lo entiendo. Nunca me he sentido mal en estos días que dan por ocultar las muchachas. No sé qué ha pasado. Laurencio se ha convertido en mi mejor acompañante. Me mima. Se preocupa porque me siento mal. Trata de animarme. En la noche, que he tenido que levantarme a "hacer las mayores", como ridículamente dicen las estudiantes de los colegios de monjas, Laurencio se despierta y, aun cuando yo no quiero, me acompaña a un lugar retirado, se queda prudentemente a algunos metros de mi [sic], y yo me pierdo en la oscu- ridad ocultando mi pena. (Zago 1975a: 20)

¿Dónde está la épica en un revolucionario con trastornos celíacos? ¿Dónde hallar el terror de un feroz delincuente en alguien avergonzado por molestar a otro con su enfermedad? La cotidianidad de los eventos y su no menos singular respuesta a sus problemas establecen como mínimo una empatía vivencial con quien lee su historia pues identifica, asocia las actitudes y el carácter de sus protagonistas con los suyos. Además, el afán de la autora por el registro del mundo rural y sus actores, aunado a una ausencia de estilización de la prosa, establece en el receptor una percepción llana de la información que le permite asignarle un estatus de verosimilitud. Al ser más simples su mensaje y su anécdota, su credibilidad aumenta, con lo cual parte del objetivo subyacente en estas palabras se instila poco a poco en sus páginas: no se trataba de gigantes actuando en un mundo de enanos, sino de enanos que por propia voluntad habían puesto sobre sus hombros el cuerpo de un gigante.

rialismo, el testimonio busca establecer identidades entre el protagonista y el colectivo, entre el investigador y el protagonista $-\mathrm{y}$, por consiguiente, entre lector, investigador, protagonista y el colectivo, entre el sujeto presente y el objetivo histórico y entre lo escrito y el lenguaje hablado, vivo". 
La geografía humana, pues, es capital dentro de las historias. Conocer aspectos de la vida de jóvenes de la zona como Cirilo, "[u]n muchacho campesino que masca chimó y que habla todo pa'lante" (Zago 1975a: 36), o de Ricardo, "buenote, pero obstinado como un burro" (Zago 1975a: 54) que apoyan la causa revolucionaria es una invitación a adentrarse en nuevos matices interpretativos o por lo menos dejar de lado la satanización a priori de una serie de hombres a los que probablemente ni siquiera se había tenido la oportunidad de conocer sino solo advertir gracias a señalamientos de terceros, ${ }_{1}^{11}$ pues incluso desde una perspectiva militar no siempre la guerra contra el ejército fue sin cuartel, tal y como se percibe en una operación realizada por Marcelo, su compañero guerrillero:

Dice [Marcelo] que dos cazadores quedaron heridos. Él los montó en el jeep y prendió la máquina. "Estaban mal", dice lacónicamente. "Les expliqué que nuestra guerra no era contra ellos. Hablé unos minutos con los dos y deseé que se curaran. Uno me decía a todo sí caballero, sí caballero. A media hora del lugar de la emboscada queda el campamento. Creo que se pudieron salvar". (Zago 1975a: 177)

El conocimiento pleno de la experiencia de estos sujetos marginados del poder y hasta cierto punto de la historia conlleva en no pocas ocasiones cierta morosidad en sus tramas, las cuales contribuyen en la descripción de las dimensiones físicas, psicológicas y sociales de las personas con el fin de mostrar cuál era la verdadera dinámica del guerrillero, objetivo llamado a ganarse el interés de los que desean conocer cómo son los actores una vez en la trastienda.

En Los topos el énfasis en esto es mayor, pues la vida transcurre en un recinto carcelario y como tal la vivencia de los presidiarios (y en especial la de Armando, quien protagoniza el relato) gira en torno a un espacio cerrado donde el contacto humano es rutinario al punto de permitirles revelar su verdadero carácter una vez establecida la confianza entre sus miembros.

El primero de los ámbitos de representación de lo humano está ligado al sufrimiento. Este, al ocurrir en prisión, solo puede tener un responsable: el gobierno democrático. La conclusión aparece a medida que los abusos se hacen frecuentes. Exponer ese dolor implica imbricarlo con un segundo espacio, como lo es la personalidad de la víctima:

Ya no somos compañeros ocasionales agrupados por el azar en una celda. El tiempo y las circunstancias han ido creando entre nosotros una amistad generosa y cálida. Comprendimos que todos estamos sacudidos por fuertes tensiones emocionales. Hemos aprendido a reconocer en nosotros zonas muy sensibles de la humana condición. No nos son ajenos la tristeza y el orgullo, la nostalgia y el sueño, la impotencia y el miedo, la impaciencia y el compromiso, la ira y el amor, la melancolía y el odio, la espera. [...] A veces ocurre que algunas

\footnotetext{
11 "Es increíble saber que la mayoría de nuestros propios aliados, dirigentes o enemigos, no se habían detenido a pensar quiénes éramos esos jóvenes que un buen día habíamos salido de nuestro escenario hogareño y sin pensar mucho acudimos a un llamado donde en alguna esquina, detrás de alguna roca nos esperaba la muerte o, lo más duro, la soledad" (Zago 1993b: 30).
} 
de estas emociones se desata [...]: no vino esa visita que se ha esperado durante varios días con gran ansiedad. No llegó la carta. Prestaron a otro el libro que queremos leer. [...] un hijo está enfermo. La mujer no tiene cómo pagar el alquiler y el Partido no puede ayudar [...]. El hogar fue allanado. No se puede asistir al entierro del padre. La novia decidió no volver. [...]

Hay reunida una rica experiencia en un conjunto de hombres tan heterogéneo. Varios son campesinos de la sierra coriana [...]. Hay hombres cultos y refinados como Edgar que es un fino dibujante y un espíritu altamente sensible [...]. Hay muchos jóvenes universitarios: Víctor, Rafael, Alwilson [...] son algunos de ellos, integran el pelotón pequeñoburgués de la familia. Hay muchachos de barrio como Holmes, que llegó a la prisión temiéndole al grueso de los libros y ya se atreve a jurungar las páginas de Hegel y Marx. (Liendo 1975: 93-94)

Acá observamos otra de las estrategias composicionales de la que se valen ambos autores para la generación de esa verosimilitud tan buscada. La construcción de los personajes está marcada por una profusión de datos físicos, psicológicos y sociales que, si bien desde una perspectiva estilística los convierte en seres redondos y con cierta tendencia a cambiar conforme transcurre la anécdota, terminan por ser percibidos como seres verdaderos cuya existencia ha pasado a una escritura que hace el papel de huella de esa realidad. El empleo del detalle conforma un sustento fundamental de su lógica narrativa, el cual suele estar conectado con ciertos recursos intertextuales dispuestos en función de la capacidad que tengan de reforzar la credibilidad del relato, como ocurre con la inclusión de las cartas escritas por los combatientes en donde contemplamos su dimensión ideológica o sentimental. A esto debe añadírsele el empleo de la retórica testimonial romántica (ya explicada por Sarlo) donde la singularización de la experiencia, materializada a través de la enunciación de una voz narrativa homodiegética de focalización interna que se construye de forma coherente, estimula una afinidad capaz de zanjar las distancias habituales en el proceso de decodificación de un texto gracias a la sensación de cercanía entre el lector y el narrador.

Así, esta gama de hombres inimaginable desde la retórica oficial es la que le permite enunciar con un marcado interés que ellos no son "precisamente unos bandidos, como dice machaconamente el ministro de la Defensa. Por lo menos hay aquí [...] unos cuantos bandoleros con el alma de Robin Hood" (Liendo 1975: 95). A esto el autor le agrega el humor como elemento característico de esa vida en prisión. Personajes que chancean sobre temas sexuales a través de la parodia de términos marxistas, que vociferan malas palabras ante ciertas ocurrencias en la vida común y se reúnen no pocas veces al son de la música parecería a los ojos de muchos hasta una degradación deliberada del ideal del héroe guerrillero. Pero esta risa, esta recurrente voluntad de vivir como cualquier hombre de a pie aunque no se esté en el mundo ${ }^{12}$ no se distancia de su objetivo principal pues, como decía Voltaire, el hombre es el único animal que ríe.

12 Es la idea que manifiesta en su programa estético al colocar en el epígrafe una frase de André Malraux ubicada en La condición humana: "¡Oh, prisión, lugar donde se detiene el tiempo que sigue en otra parte!". 
Esta precisión no está exenta de un costado sombrío, especialmente desde el catalejo de la llamada moral revolucionaria. Es así como muchos de estos combatientes aparecen como seres bondadosos pero cobardes en la batalla; motivados a ejercer la lucha política por intereses altruistas e idealistas tan notables como la indisciplina con la que se desenvuelven en los frentes (para este propósito, Liendo se vale, además de la vivencia de Armando, de una narración de focalización externa y voz heterodiegética con la cual reconstruye esa dinámica del guerrillero en las montañas, la retrata y exponer la actitud ética manifestada por estos combatientes en tiempos de guerra).

Con Zago su propia reflexión y constatación de la variedad de gente con la que se encuentra es suficiente para generar sus propias ideas de lo que se vive. Una palabra peligrosa para su momento se hace visible en esta convivencia con la guerrilla: autocrítica. Como pocas novelas testimoniales del periodo, estos textos muestran los conflictos internos de la organización tanto en su índole humana como en su dimensión, digámoslo así, corporativa, lo que demuele por una parte la impresión exagerada del revolucionario como un hombre de disciplina férrea y letal ante el combate (algo impensable incluso para ellos mismos ${ }^{13}$ ) y por otra desenmascara la pretendida armonía interna de un movimiento que aspiraba a mejorar la política por medios antipolíticos. La proliferación del detalle en una tercera persona permite visualizar una serie de datos objetivos que, tejidos a través del lenguaje plástico, conforman la modalidad realista señalada por Sarlo. Los hechos, detallados en sus elementos históricamente comprobables, aparecen en un orden secuencial que cierra el paso a una potencial ambigüedad exegética e imponen un sentido convincente de lo ocurrido. De esta manera, en Los topos se observa una serie de problemas relacionados con la indisciplina, la tiranía en las relaciones de poder entre los miembros del partido y la inconsistencia de algunos miembros comunistas que no apoyan personalmente la lucha armada:

Las relaciones entre los bisoños guerrilleros son poco cordiales. Hay rencillas secretas. La mayoría de los hombres con responsabilidad en la dirección ordenan con un acento autoritario, casi despótico. Además hay demasiados jefes de tropa. Una palabra se repite con demasiada frecuencia: fusilar. (Liendo 1975: 70-71)

Hay signos de desagrado en algunos de los combatientes, lamentan que las botas se han roto muy pronto o que no tienen plásticos para cubrirse o que no reciben de la retaguardia suficiente ayuda.

-Uno jodiéndose y esos pendejos en Caracas bonchando y hablando paja-dice alguien. (Liendo 1975: 105)

\footnotetext{
13 Sobre el tema Zago señalará en una entrevista lo siguiente: "[Y]o después he conocido por casualidad militares, y estoy sorprendida de la impresión que ellos tenían de nosotros. Que éramos unos ogros aterradores, algo así" (Frielich de Segal s.a: 298).
} 
—Estos hombres no tienen disciplina, Cruz -dice enfáticamente [Gonzalo Castaño].

-Están muy fatigados por la marcha, pero creo que serán buenos soldados -dice el primer comandante.

- Vamos a ver, ordénales formar - dice Gonzalo.

Cruz imparte la orden: ¡Formación! Los dos tenientes la repiten con insistencia: ¡Formación! ¡Formación! Cuatro jefes de escuadra tratan de ponerla en práctica. ¡Formación! Pocos hombres se ponen de pie rápidamente y toman su fusil, la mayoría se incorpora con lentitud, algunos continúan mordisqueando el papelón sin atender la orden. Cuando después de largo tiempo todos han ocupado su lugar en la formación, Gonzalo, en tono escéptico, le dice al comandante: "¿Y estos son los soldados que mañana comienzan a combatir el ejército regular?". (Liendo 1975: 82-83)

Lo dicho hasta ahora muestra los intentos narrativos de construir una personalidad tanto personal como colectiva que se corresponda con los valores que ellos consideraban que representaban, por lo cual se hace pública la expresión de lo que los autores asumían como "su identidad", para lo cual la representación literaria de sus vidas era apenas una herramienta indispensable para lograrlo. El discurso testimonial devino así en voz de esos sujetos "silenciados" y "anónimos" que anhelaban según Beverley interpelar al receptor "en su función de lector/intérprete del testimonio, en tanto que aliado con ese sujeto (y hasta cierto punto dependiente de él)" (2011b: 51).

En Aquí no ha pasado nada ocurre con el mismo tenor los problemas expuestos líneas arriba, con la diferencia de que no está presente la "modalidad realista" de los eventos sino más bien la "modalidad romántica", pues solo se proyecta la voz de Morela, quien percibe cómo ese año y medio en el cual se desenvolvió como miembro del partido ha sido poco menos que un fracaso notorio. Esto evidencia el carácter de un ser decepcionado con un proyecto al cual no le ve viabilidad ni correspondencia con sus aspiraciones humanas (algo que, por cierto, ya Liendo había expresado en la voz de Armando: "Me voy a la cama y no puedo dormir. Es una lucha contra los ídolos, es el fuego que una vez consumió a Cristóbal en la rebelión. Nunca más tendré ídolos, nunca más" [1975: 162]):

Cinco campesinos perseguidos por el ejército piden su incorporación a las guerrillas. Simplemente se presentaron con una semi-sonrisa y como quien pide pan dijo uno de ellos: "Camará, justedes siempre dicen que cuando la guerra llegara necesitarán de jombres, puee aquí están cinco pa' servir a la revolución" ¿Alguna vez has tragado aceite? ¿Eso que te pasa por la garganta como sin acabar de pasar? Mi saliva se convirtió en aceite espeso. Debe ser que lloré para adentro, como ya no lo sé hacer para afuera... Fue un poco difícil explicarles a los camaradas que mejor era que se fueran para algún caserío lejano, donde tuvieran familia ¿Cómo decirles la verdad? [sic] ¿Cómo decir: mire compañero, todo eso que le hemos dicho de incorporarse a las guerrillas, todo eso no puede ser, no hay armas, no hay ropa, no hay balas, no hay comida, no hay botas, no hay hamacas, no hay morral, no hay un coño. Hemos mentido. Pero no hay que decir nada, porque nosotros no hemos mentido. Nosotros sabemos que la única forma de tomar el poder es a través de la lucha armada, y nosotros 
queremos tomar el poder. Simplemente: queremos tomar el poder. Si entendieran los camaradas de la ciudad el dolor que produce oír que las botas no llegan porque un compañero, por negligencia o por miedo, las detuvo en una estafeta y allí están. $O$ saber que tres meses antes de que comenzara este maldito cerco, pedimos al Comité Regional que nos mandara resmas de papel y se nos respondió: "¿Para qué necesita un guerrillero papel?" O suplicar una carta de aliento [sic]. ¿O es que esta guerra es nuestra solamente? (Zago 1975: 189)

Estas muestras públicas de desencanto por parte de miembros del Partido Comunista de Venezuela solían desmoralizar tanto o más que las derrotas efectuadas por sus enemigos a lo largo de los sesenta. La negatividad de ciertos pasajes tiene más peso si se toma en cuenta que quienes lo construyeron vivieron en las entrañas de un proceso que defendieron hasta el final. Con todo, su aparición no significó una condena social o grupal para sus autores, como sí había ocurrido con quienes denunciaron esta realidad en el apogeo de la lucha (pensemos por ejemplo en Entre las breñas [1963] de Argenis Rodríguez). Al tratarse de tiempos de derrota, las condiciones de dicha enunciación jugaban a su favor para romper con los objetivos habituales que motivaban su elaboración. La novedad de este tipo de narrativa surgió entonces cuando la narración se enarboló con toda su retórica para delatar la condición humana de los testigos, en detrimento de una tradicional exposición sistemática de la violencia cuyas causas fueran atribuidas a las condiciones opresivas promovidas por la élite democrática, burguesa y (dentro de su horizonte de pensamiento) servil a los intereses imperiales norteamericanos, por lo que cualesquiera de las posibles interpretaciones en estos testimonios parecían haberse despolitizado.

Pero se trataba solo de eso, de una apariencia, pues detrás de este acto había algo profundamente político, si bien la sutileza de esta acción lo encubría. Frente al lenguaje que emanaba desde una posición hegemónica aparecía otro cuya posición era opuesta en todos los ámbitos, como puede percibirse en el contraste entre el discurso racional y abstracto de las alocuciones de Betancourt y el emotivo y concreto expuesto en las narraciones de los guerrilleros; entre el empleo de un aparato comunicacional estatal que mediante la radio y la televisión publicitaba una imagen peyorativa de los insurgentes frente a las escasas ediciones de sus novelas; entre unas palabras que, amparadas desde una posición victoriosa, lograban calar en la conciencia colectiva y otras que, relegadas a un espacio de influencia marginal, buscaban desarticular los símbolos del poder. Aunque sus autores no estuviesen conscientes de ello, con este gesto su condición subalterna se expresaba con fuerza desde una perspectiva política, pues construían una identidad que al ser difundida por vía libresca operaba en el espacio público no como una idea en sí (aunque ellos escribían con el pleno convencimiento de estarse exponiendo "tal cual eran") sino para sí, cuya enunciación funcionaba como un contradiscurso que aspiraba a destruir esas interpretaciones creadas por las élites políticas, lo que potencialmente implicaba una eventual salida de su condición subalterna para adquirir en cambio un estado de hegemonía. 
Lo dicho líneas arriba nos permite finalizar haciendo una conexión con lo expresado sobre el fenómeno de la violencia simbólica y explicar el proceso de desarticulación que traen consigo. En la medida que la narración se aboca por (re)presentar la vivencia personal del escritor deslastrada de cualquier matiz doctrinario se fortalece un discurso subjetivo que contrapone una nueva imagen del guerrillero que rechaza, cuestiona y socava al estereotipo enunciado desde las altas instancias del poder. Esto demuestra una lucha por el control de los significantes con los cuales interpretar la identidad de los sujetos históricos, así como una aspiración a delatar el carácter ideológico de tal imposición, ya que al utilizar algunos de los recursos retóricos del relato testimonial con los cuales hacer de la vida misma un sustento infalible de transmisión de la verdad todo los demás deviene en exégesis falsas de la realidad, tal cual lo señaló el marxismo clásico. ${ }^{14}$ Así, aunque la escritura testimonial de la guerrilla ciertamente no hace énfasis en el martirio del cuerpo ni en la crueldad de un sistema al que por inferencias habríamos de tildar de tiránico, sí contribuye desde la palabra escrita a que sectores marginales desde la esfera política puedan "to wage their struggle for hegemony in the public sphere from which they were hitherto excluded or forced to represent stereotypes by the reigning elites" (Yúdice, 1996: 53). ${ }^{15}$

\section{CONCLUSIONES}

La producción testimonial venezolana se remite a tiempos tan tempranos del siglo xx como el año 1921, momentos en los cuales aún no figuraba en el panorama cultural como un género discursivo propio, y tiene tres momentos de aparición precisos, a saber: después de las dictaduras de Juan Vicente Gómez y las Fuerzas Armadas de Venezuela y luego de la lucha guerrillera contra el sistema democrático. A pesar de tratarse de textos de urgencia que delatan una condición de marginalidad por parte de quienes escriben, sus objetivos no se repiten en cada uno de estos periodos. Esto se debe a que, a diferencia de los relatos que surgieron una vez defenestrados los gobiernos tiránicos, hubo otra camada de textos que aparecieron desde una posición clara de derrota, pues sus integrantes no pudieron derrocar al sistema combatido. Es el caso de los testimonios de la guerrilla y su interés es otro: desmantelar la imagen que pro-

\footnotetext{
14 En una carta fechada en Londres el 14 de julio de 1893, Federico Engels explicó algunos de los componentes esenciales del término a F. Mehring de la siguiente manera: "La ideología es un proceso que se opera por el llamado pensamiento consciente, pero con una conciencia falsa. Las verdaderas fuerzas propulsoras que lo mueven, permanecen ignoradas [...]; de otro modo, no sería tal proceso ideológico. Se imagina, pues, fuerzas propulsoras falsas o aparentes" (Silva 2013 188). Esto implicaría para Ludovico Silva que, desde la concepción marxista clásica, la ideología juega siempre "un papel encubridor y justificador de las clases materiales" (2013: 37). Este proceso es totalmente visible en un conflicto armado en donde las ideas de la clase política dominante se imponen como verdades absolutas con las cuales legitimar la represión sobre el oponente. El discurso testimonial de mediados de los setenta con base en el desarrollo de una experiencia humana despojada del discurso doctrinario se instala en el espacio público, pues, como modo de desenmascarar el matiz artificioso de ese discurso.

15 "Librar sus luchas por la hegemonía desde la esfera pública de la cual habían sido excluidos hasta entonces o forzados a representar estereotipos por las élites reinantes".
} 
yecta social, política e históricamente quienes detentan el poder político, con lo cual marca una ruptura con la experiencia de otros procesos similares como el testimonio nicaragüense.

Para esto, Ángela Zago y Eduardo Liendo se plantearon la exposición narrativa de sus experiencias como recurso probatorio de su condición de ser humano -uno con las mismas condiciones morales y espirituales de cualquier ciudadano- frente a los simbólicamente violentos motes de "asesinos" y "terroristas" emitidos durante y después de la refriega por el bando vencedor. El discurso testimonial se vale aquí de una retórica que, una vez puesta en el papel se espera que produzca en el lector un efecto de verosimilitud que gane tanto su solidaridad como su favor en esa pugna por una representación del sujeto subalterno que lo libere de dicha condición, pues como decía Beverley este género lo obliga a confrontar "su capacidad como sujeto de un proyecto de transformación que aspira a ser hegemónico por derecho propio" (2011b: 45).

Uno de esos aspectos se encuentra en el empleo de una estética de factura realista que construye a los personajes como si fueran personas, es decir, les otorga suficientes atributos como para establecer en la mente de los receptores una compatibilidad con su mundo. El detalle humano y geográfico es la base de lo que crean. Otro aspecto fundamental está relacionado con los paratextos, los cuales al colocarse conjuntamente con los escritos contribuyen a coordinar su sentido, desambiguarlo y legitimarlo como contingente de un mundo que fue. De esta manera los autores se adentran en la configuración de su identidad con un lenguaje propio como recurso contestatario contra una ideología hegemónica que ha arropado a los vencidos con un sentido impuesto, vale decir, violento.

\section{OBRAS CITADAS}

Betancourt, Rómulo (1968): La revolución democrática en Venezuela. 1959-1964, cuatro tomos. Caracas, Imprenta Nacional.

— (1968 a): "El terrorismo político". En La revolución democrática en Venezuela. 19591964, tomo I. Caracas, Imprenta Nacional, pp. 202-209.

— (1968 b): "Respeto y defensa del orden constitucional". En La revolución democrática en Venezuela. 1959-1964, tomo III. Caracas, Imprenta Nacional, pp. 246-252.

_ (1968 c): "Cuatro años de gobierno constitucional". En La revolución democrática en Venezuela. 1959-1964, tomo III. Caracas, Imprenta Nacional, pp. 301-310.

— (1969d): Hacia una América Latina democrática e integrada. Madrid, Taurus.

— (1969d): "El problema del comunismo insurreccional". En Hacia una América Latina democrática e integrada. Madrid, Taurus, pp. 121-129.

Beverley, John (1987a): "Anatomía del testimonio", Revista de Crítica Literaria Latinoamericana, año XIII, n. ${ }^{\circ} 25$, pp. 7-16.

— (2011b): Políticas de la teoría. Ensayos sobre subalternidad y hegemonía. Caracas, Centro de Estudios Latinoamericanos Rómulo Gallegos.

Carrera Damas, Germán (2013): Rómulo histórico. Caracas, Alfa. 
Colás, Santiago (1996): "What's wrong with representation?: Testimonio and Democratic Culture". En Georg M. Gugelberger (ed.): The real thing. Testimonial discourse and Latin America. Duke University Press, pp. 161-171.

Cubas, Romhy (2016): "Eduardo Liendo y la vigencia de El mago de la cara de vidrio", El Estímulo, versión en línea en <http://elestimulo.com/blog/entrevistaeduardo-liendoel-destiempo-subversivo-de-los-recuerdos/> [última visita: 8.7.2016].

Engels, Federico (2013): "Engels a F. Mehring". En Ludovico Silva: Teoría de la ideología / Contracultura. Caracas, Fundación editorial el perro y la rana, pp. 187-190.

Freilich de Segal, Alicia (s.a.): Entrevistados en carne y hueso. Caracas, Librería Suma.

- (s.a.): "Entre ayer y hoy. Ángela Zago". En Entrevistados en carne y hueso. Caracas, Librería Suma, pp. 291-311.

Foucault, Michel (1992): El orden del discurso. Buenos Aires, Tusquets.

Gugelberger, Georg M. (1996): The real thing. Testimonial discourse and Latin America. Duke University Press.

Grüner, Eduardo (1998): "El retorno de la teoría crítica de la cultura: una introducción alegórica a Jameson y Žižek". En Fredic Jameson y Slavoj Žižek (eds.): Estudios culturales. Reflexiones sobre el multiculturalismo. México D. F., Paidós, pp. 11- 67.

Jameson, Frederick, y Žižek, Slavoj (1998): Estudios culturales. Reflexiones sobre el multiculturalismo. México D. F., Paidós.

Lejeune, Philippe (1994): "El pacto autobiográfico". En El pacto autobiográfico y otros estudios. Madrid, Megazul-Endymion, pp. 49-87.

Liendo, Eduardo (1975): Los topos, Caracas, Monte Ávila.

Ojeda, Fabricio (2009): Carta de renuncia al Congreso Nacional. Caracas, Ediciones de la Presidencia de la República.

Ortega, Julio (comp.) (1993): Venezuela: fin de siglo. Actas del simposio Venezuela: cultura y sociedad al fin de siglo (Brown University, 1991). Caracas, Ediciones La Casa de Bello.

Rueda Estrada, Verónica, y Vázquez Medeles, Juan Carlos (2015): "Testimonio nicaragüense: de los Sandinistas a la inclusión de los Contras. Por una polémica memoria contrarrevolucionaria", Kamchatka. Revista de Análisis cultural, número especial "Avatares del testimonio en América Latina: tensiones, contradicciones, relecturas...", n. ${ }^{\circ} 6$, pp. $463-490$.

Sarlo, Beatriz (2007): "La retórica testimonial". En Tiempo pasado. Cultura de la memoria y giro subjetivo. Una discusión. Buenos Aires, Siglo XXI, pp. 59-94.

Silva, Ludovico (2013): Teoría de la ideología / Contracultura. Caracas, Fundación editorial el perro y la rana.

Sklodowska, Elzbieta (1996): "Spanish American Testimonial Novel: Some Afterthoughts". En Georg M. Gugelberger (ed.): The real thing. Testimonial discourse and Latin America. Duke University Press, pp. 84-100.

Yúdice, Georg (1996): "Testimonio and Posmodernism". En Georg M. Gugelberger (ed.): The real thing. Testimonial discourse and Latin America. Duke University Press, pp. 42-57.

Zago, Ángela (1975a): Aquí no ha pasado nada, Caracas, Publicaciones Españolas.

— (1993b), "Testimonio y verdad". En Julio Ortega (comp.): Venezuela: fin de siglo. Actas del simposio Venezuela: cultura y sociedad al fin de siglo (Brown University, 1991). Caracas, Ediciones La Casa de Bello, pp. 27-33.

Žižek, Slavoj (2009): Sobre la violencia. Seis reflexiones marginales. Buenos Aires, Paidós.

188 Pasavento. Revista de Estudios Hispánicos, vol. VI, n. ${ }^{1}$ (invierno 2018), pp. 167-188, ISSN: 2255-4505 